\title{
EXCRETION OF SODIUM PREGNANEDIOL GLUCURONIDATE IN URINE OF NORMAL HUMAN PREGNANCY ${ }^{1}$
}

\author{
BY CARL BACHMAN, DOROTHY LEEKLEY, AND H. HIRSCHMANN \\ (From the Department of Obstetrics and Gynecology and the Gynecean Hospital Institute of \\ Gynecologic Research, University of Pennsylvania, Philadelphia)
}

(Received for publication June 17, 1940)

Venning and Browne ( 1 to 7 ) have shown that sodium pregnanediol glucuronidate is excreted in urine of human pregnancy in concentrations which become increasingly higher as gestation approaches term. Although this demonstration has been repeatedly confirmed ( 8 to 16 ), relatively few workers have studied the precise levels and ranges of normal excretion, or have secured long-continued records of output in individual parturients. As a consequence, there has not been complete agreement concerning the quantitative aspects of normal excretion. We have accordingly studied the urines of a number of healthy women throughout pregnancy. In addition to corroborating the original findings of Venning and Browne, our studies have thrown light upon a number of points which have previously been in question, and have supplied data concerning excretion during multiple pregnancy.

\section{METHODS}

Twenty-four hour volumes of urine were collected at weekly intervals from early pregnancy to the onset of labor. The specimens were delivered to the laboratory within an hour of the completion of their collection, and were then kept at 0 to $5^{\circ}$ until their work-up, which in no instance was delayed longer than 15 hours.

The work-up of the urines was carried out in accordance with Venning's modified method (3), except that $3.0 \mathrm{cc}$. of water were used for re-dissolving the first precipitates obtained from acetone. From the 24-hour collections, aliquots were selected which were expected to yield at least $15 \mathrm{mgm}$. of the glucuronidate. When the pure compound was added to pregnancy urines in this amount, recoveries were quantitative with the procedure employed. This did not justify the assumption that the recoveries of the pre-formed glucuronidate of such urines were also quantitative, since the addition of $15 \mathrm{mgm}$. of pure compound to urines containing no glucuronidatei.e., male or menopausal urine-resulted in recoveries of only about 85 per cent. Nevertheless, the yields of preformed compound from pregnancy urine were calculated

1 Aided by a grant from the Penrose Fund of the American Philosophical Society. on the assumption that they represented complete recoveries.

The pure reference compound was obtained by extracting the final product of the modified Venning procedure with butanol from an alkaline solution, and then evaporating the extract to dryness, precipitating the residue from water with acetone and recrystallizing the product from ethanol. Examination of a sample, dried at room temperature in vacuo over $\mathrm{P}_{2} \mathrm{O}_{3}$, gave the following analysis ${ }^{2}$ :

Calculated for $\mathrm{C}_{27} \mathrm{H}_{48} \mathrm{O}_{8} \mathrm{Na} . \mathrm{H}_{2} \mathrm{O} . \mathrm{C}, 60.41 ; \mathrm{H}, 8.45 ; \mathrm{Na}, 4.29$

$\mathrm{C}_{21} \mathrm{H}_{48} \mathrm{O}_{8} \mathrm{Na} . \ldots . \mathrm{C}, 62.51 ; \mathrm{H}, 8.36 ; \mathrm{Na}, 4.44$

Found $. \ldots \ldots \ldots \ldots \ldots \ldots \ldots . C, 62.35 ; \mathrm{H}, 8.21 ; \mathrm{Na}, 4.63$

These findings, together with our data on the loss of weight during drying, indicated that the pure compound did not contain a molecule of water of crystallization, as stated by Venning and Browne (1), ard that a monohydrate could not be readily obtained. Its melting point was found to vary with the rate at which samples were heated, being $277^{\circ}$ (corrected) when the temperature was raised $4^{\circ}$ per minute. Melting was accompanied by decomposition.

The pregnanediol glucuronidate isolated during the systematic examinations of pregnancy urine was identified in every instance by a melting point determination, standardized to the above rate of heating. In general, the preparations obtained from urine of early and mid-pregnancy were relatively colorless crystals which rarely melted at temperatures lower than $273^{\circ}$ (corrected). Those obtained from urine of late pregnancy were brown and semicrystalline, and showed melting points 6 to $10^{\circ}$ lower than that of the standard preparation. Although it was obvious that the impurities present in such samples caused over-estimates of the amounts of glucuronidate obtained, no correction was applied to the yields. However, preparations which gave melting points more than $10^{\circ}$ lower than the standard were further purified before weighing.

In conformity with previous reports, our results have been recorded in terms of free pregnanediol. Since our glucuronidate products were dried in vacuo before weighing, a factor based upon the molecular weight of anhydrous pregnanediol glucuronidate-i.e., $320 / 518$, or 0.618 -was employed for this conversion.

\section{OBSERVATIONS}

Single-fetus gestation. Data were obtained from 6 patients whose health remained normal

${ }^{2}$ Microanalysis by Mr. Wm. Saschek. 


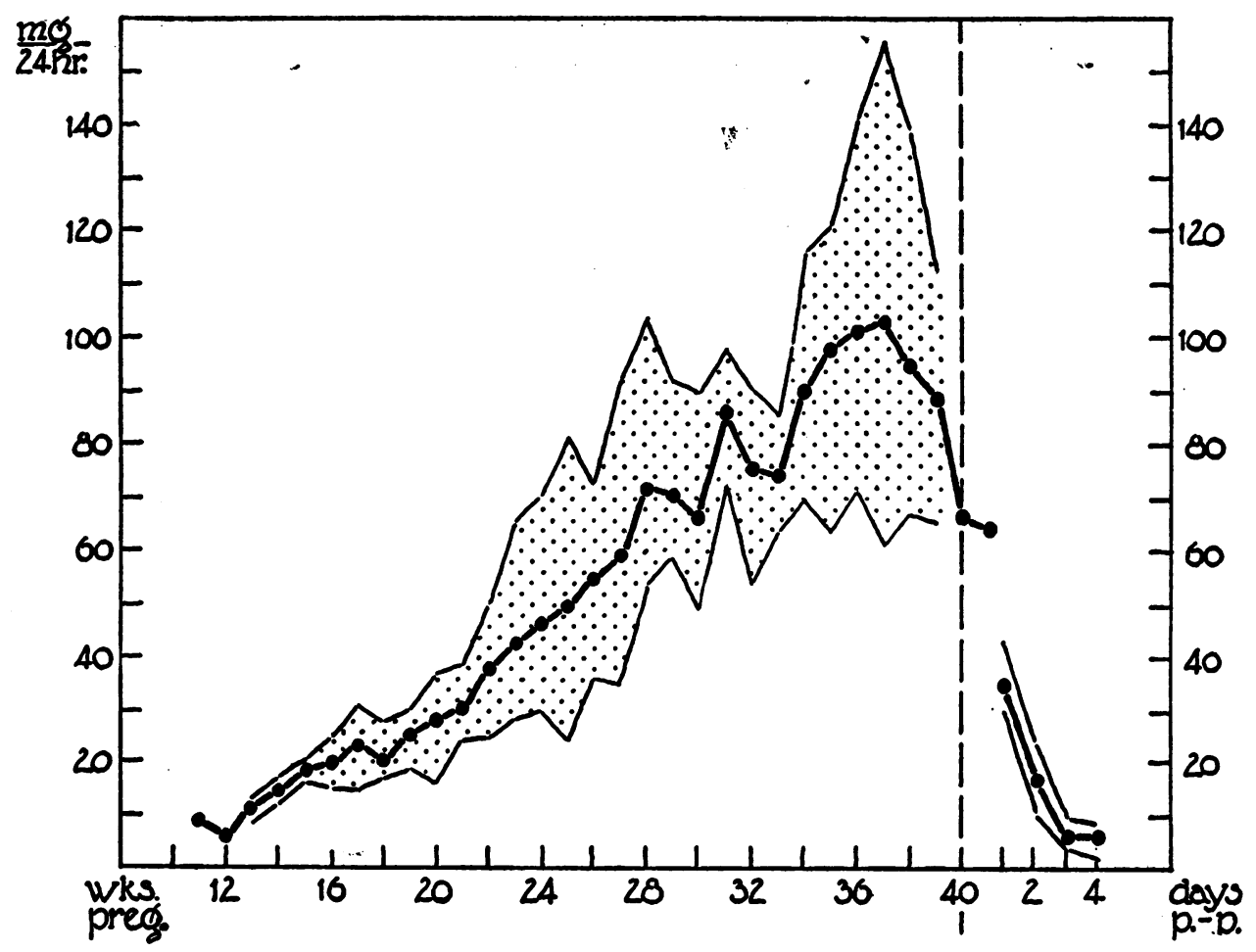

Fig. 1. Pregnanedol Excretion in Normal Pregnancy

Abscissa represents menstrual age of pregnancy in weeks (wks. preg.), and includes the first few postpartal days (days p.-p.). Ordinate shows output of pregnanediol in mgm. per 24 hours. Heavy dotted line represents the means, light lines (enclosing stippled area) the extremes, of daily excretion for various weeks of gestation in a group of 6 women. All labors spontaneous in onset. Average duration of pregnancy for the group, 279 days. Average crown-heel length of infants, $49.2 \mathrm{~cm}$.; average weight, 3218 grams. Average placental weight, 630 grams.

during the period of study. The results of 144 determinations were available for consideration, representing an average of 24 serial weekly examinations of each patient prior to the onset of labor. It was noted that with each patient these examinations had fallen upon dates which could be oriented in terms of weekly intervals (plus or minus a day) from either the date of the last menstruation or the date of delivery. It was thus possible to arrange the data in terms of the mean and extreme excretions of the group for each week of gestation.

Such an arrangement of the data has been made in Figures 1 and 2, where the orientations have been based, respectively, upon the menstrual age of the pregnancies and upon the number of weeks remaining before delivery. That the two methods of orienting the data should not have yielded identical curves of average excretion was due to the fact that the menstrual age of the pregnancy at the time of delivery in 3 of the 6 patients deviated from the mean of $\mathbf{4 0}$ weeks for human pregnancy by 1 to 2 weeks, i.e., 38,39 and 42 weeks, respectively. The method of orientation and the resultant curves illustrated in Figure 2 have been regarded as preferable to those of Figure 1 for the following reasons: First, the menstrual histories were not completely dependable in certain of the cases; second, the infants who were born to each of these mothers met the accepted criteria for full fetal maturity in respect to their skeletal dimensions and body weights regardless of the presumptive menstrual ages of the gestations; third, the deviations of the extreme values from the mean values of excretion were smaller in Figure 2 than in Figure 1; and, finally, Figure 2 reflected certain characteristics of the patients' individual records of excretion more fully than did Figure 1.

Prior to the 20th week of pregnancy mean 


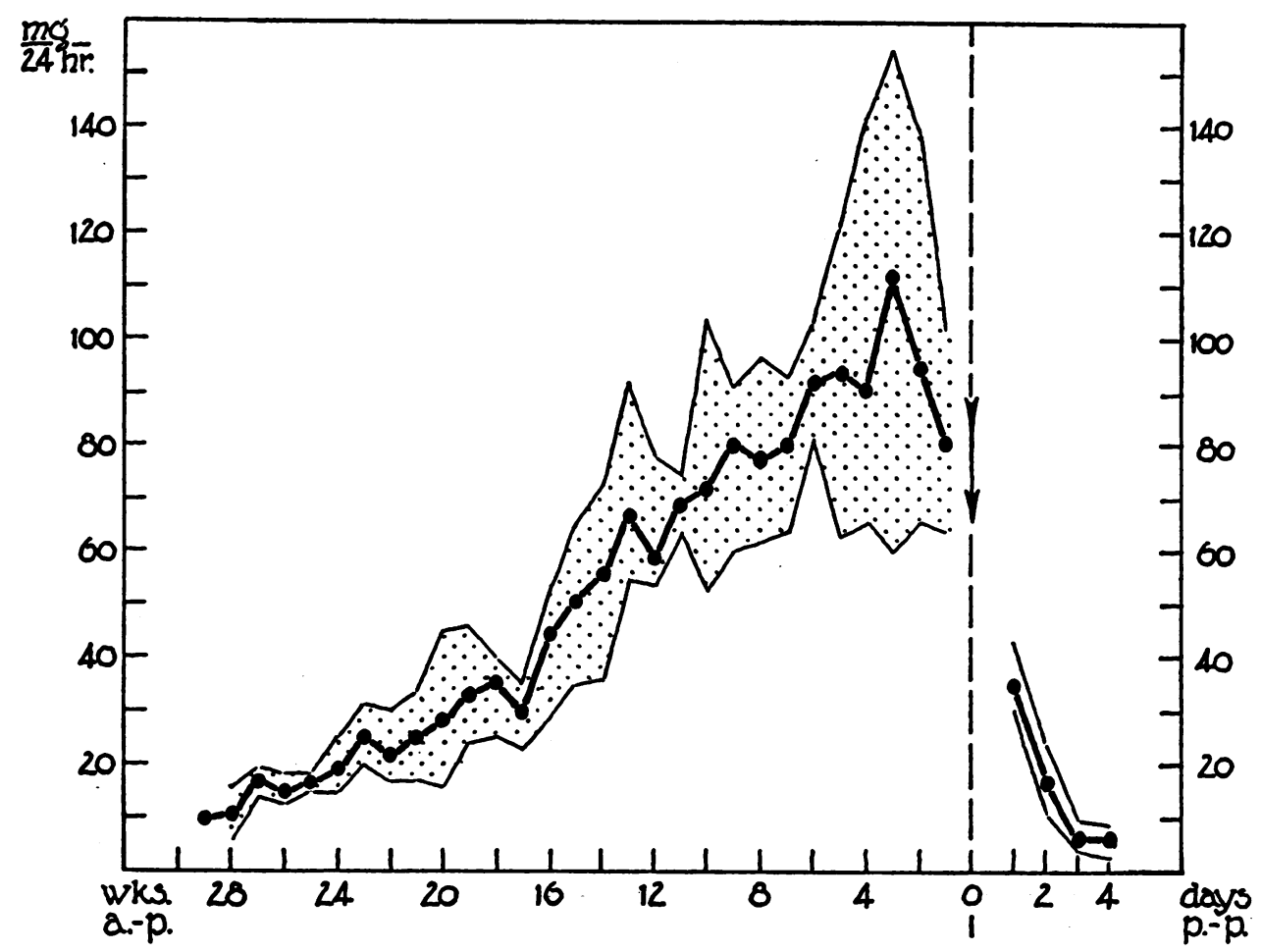

Fig. 2. Pregnanediol Excretion in Normal Pregnancy

Same as Figure 1, except that the data for various periods of pregnancy are arranged in terms of intervals remaining before labor, or weeks antepartum (wks. a.-p.).

daily excretions of pregnanediol did not exceed $30 \mathrm{mgm}$. Thereafter, the amounts of such excretions were found to rise by increments of about 20 mgm. per month until the 36th week, at which time a peak level of about 100 mgm. per 24 hours was attained. Following this the daily excretions tended to fall off in amount, so that by the 39th week a mean level of $80 \mathrm{mgm}$. per day was the rule. According to Figure 2 the amount of any patient's daily excretion did not appear to deviate by more than \pm 20 per cent from the mean excretion of the group for a corresponding period. Among the various patients these differences tended to be most marked in late pregnancy. No patient's individual record of output was found to lie continuously above or below the mean curve for the group.

The pre-labor peak and fall in excretion, illustrated in Figures 1 and 2, were apparent in the individual excretion records of 5 of the 6 patients studied. In addition, transient cyclic fluctuations, recurring at monthly intervals, were clearly visible in the records of 4 of these patients (see also the averaged data of Figure 2). These fluctuations were not paralleled by similar variations in the urine volume output. Moreover, an investigation of the latter point, illustrated in Table I, showed that when urine volume and pregnanediol output

TABLE I

Absence of correlation between urine oolume output and excretion of pregnanediol glucuronidate during short consecutive intervals

\begin{tabular}{c|c|c|c|c}
\hline \hline $\begin{array}{c}\text { Case } \\
\text { number }\end{array}$ & $\begin{array}{c}\text { Days } \\
\text { antepartum }\end{array}$ & $\begin{array}{c}\text { Collection } \\
\text { period }\end{array}$ & $\begin{array}{c}\text { Urinary } \\
\text { volume }\end{array}$ & $\begin{array}{c}\text { Pregnanediol } \\
\text { glucuronidate }\end{array}$ \\
\cline { 2 - 4 } 1 & \multirow{3}{*}{1} & hours & cc. & mgm. \\
& 98 & 6 & 1100 & 20.8 \\
& & 6 & 620 & 15.4 \\
& & 6 & 420 & 24.0 \\
& & 6 & 375 & 22.8 \\
& 31 & 6 & 230 & 30.1 \\
& & 6 & 500 & 26.9 \\
& & 6 & 350 & 32.6 \\
& & 6 & 575 & 31.2 \\
& & 6 & 160 & 46.2 \\
& & 6 & 185 & 37.8 \\
& & 6 & 160 & 19.4 \\
& & 6 & 140 & 14.3 \\
\hline
\end{tabular}




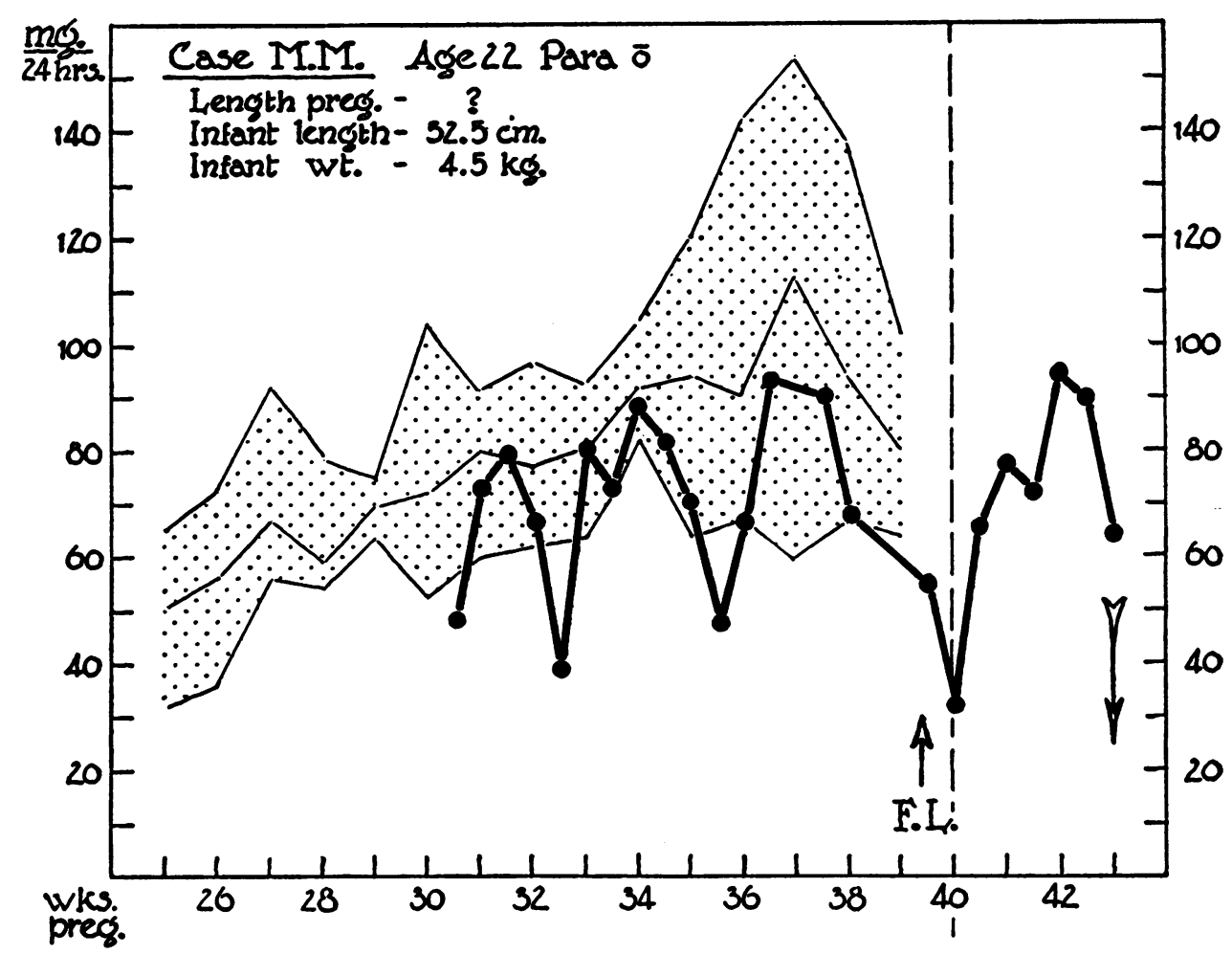

Fig. 3. Cyclic fluctuations of Pregnanediol Excretion During Late Pregnancy in a Primigravida

Excretion at twice-weekly intervals (heavy dotted line) is plotted against a background (stippled area) of the normal ranges of pregnanediol output for the period studied. False labor (F.L.) occurred at 40th week. True labor, and the birth of an oversize postmature infant, occurred at $43 \mathrm{~d}$ week.

were both examined during short consecutive intervals, there was no general relation between them either at periods of pregnancy, when the rate of pregnanediol excretion was relatively constant, ${ }^{3}$ or immediately prior to labor when the rate was falling precipitously.

In order to verify the existence of these cyclic fluctuations in the excretion of pregnanediol, the urine of a seventh patient was examined at twiceweekly intervals during the last 3 months of gestation. The results, plotted in Figure 3, fully confirmed those obtained in the original group of patients.

Multiple pregnancy. Results were obtained for short periods of gestation from 4 cases of twin, and 1 case of triplet pregnancy. They have been

\footnotetext{
8 In view of this finding we are currently investigating the possibilities of substituting 12-hour specimens for 24hour collections of urine in the study of pregnanediol excretion in pregnancy.
}

plotted in Figure 4, together with data concerning the dimensions and weights of the infants and placentas. Information concerning the maternal health of these cases has been included (see Table II) in order that this factor could be considered in evaluating the probable physiologic significance of the results. With the exception of the inexplicably high level of excretion exhibited during early pregnancy in one case, the results indicated that pregnanediol output in these cases of multiple pregnancy did not exceed the levels observed at corresponding periods of single-fetus gestation.

Puerperium. Results covering the first 5 days of the puerperium were obtained from 5 patients whose excretions were normal during pregnancy. In spite of the use of an in-dwelling catheter for obtaining the urine free of contamination with lochial discharges, it was found that the glucuronidate isolated from puerperal urine was more 


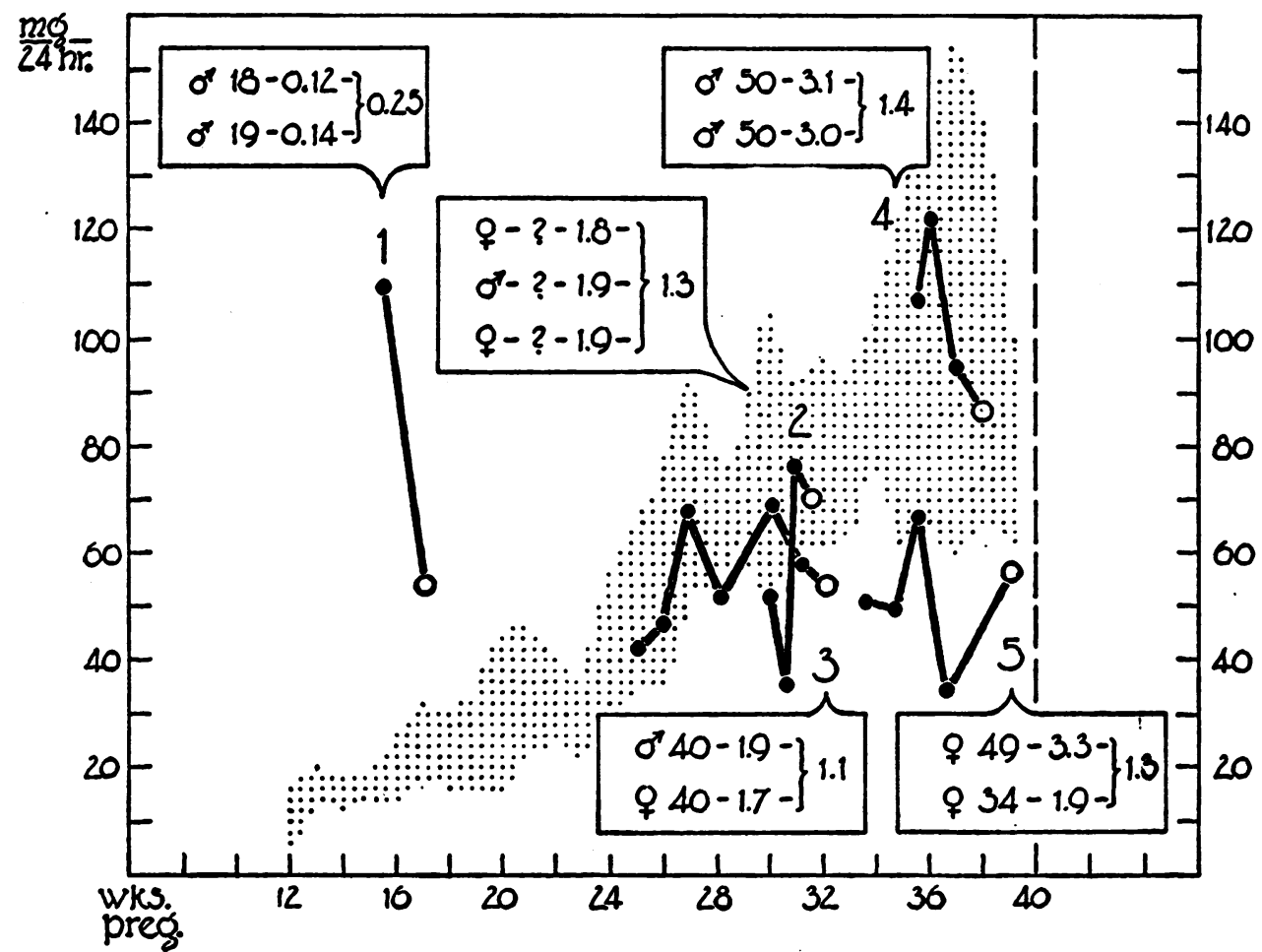

Fig. 4. Pregnanediol Excretion in Multiple Pregnancy

Data for short periods of gestation in 4 cases of twin, and 1 case of triplet pregnancy are plotted against a background (stippled area) of normal ranges of pregnanediol excretion for single-fetus gestation. Each heavy dotted line represents excretion in an individual patient, and is identified by a case number; by the use of these numbers, the clinical data concerning each patient may be located in Table II. The symbols and numerals enclosed within the brackets represent, respectively, the sex, crown-heel length (in $\mathrm{cm}$.), and weight (in $\mathrm{kgm}$.) of the infants, and the weight (in $\mathrm{kgm}$.) of the combined placentas for each patient.

impure than that obtained from the same patients during pregnancy. In each instance it was necessary to purify this product before precipitates possessing satisfactory melting points could be obtained for weighing. The results, recorded in Figures 1 and 2, showed a fair degree of constancy among the 5 patients. About $30 \mathrm{mgm}$. of pregnanediol, on the average, were excreted during the 24 hours following delivery. Material of low melting point, averaging 7 to $10 \mathrm{mgm}$., was still recoverable on the 5 th puerperal day, but it probably contained little or no pregnanediol glucuronidate.

\section{DISCUSSION}

The findings of the present study, like those of Venning, Henry and Browne, which they confirm, support the conclusion that the urinary excretion

TABLE II

Clinical data in 5 cases of multiple gestation

\begin{tabular}{|c|c|c|c|c|c|c|}
\hline $\begin{array}{c}\text { Case } \\
\text { number }\end{array}$ & Age & Gravida & $\begin{array}{c}\text { Number of } \\
\text { fetuses }\end{array}$ & Maternal health during pregnancy & $\begin{array}{l}\text { Menstrual age } \\
\text { of pregnancy } \\
\text { at termination }\end{array}$ & Nature of termination \\
\hline $\begin{array}{l}1 \\
2 \\
3 \\
4 \\
5\end{array}$ & $\begin{array}{l}22 \\
20 \\
35 \\
33 \\
36\end{array}$ & $\begin{array}{l}\text { II } \\
\text { XVI } \\
\text { III } \\
\text { V }\end{array}$ & $\begin{array}{l}2 \\
2 \\
3 \\
2 \\
2\end{array}$ & $\begin{array}{l}\text { Premature separation of placenta at } 16 \text { weeks } \\
\text { Malnutritional anemia and edema } \\
\text { Malnutritional anemia and edema } \\
\text { Malnutritional anemia and edema } \\
\text { Malnutritional anemia and edema }\end{array}$ & $\begin{array}{c}\text { weeks } \\
17 \\
32 \\
32 \\
38 \\
39\end{array}$ & $\begin{array}{l}\text { Hysterotomy } \\
\text { Spontaneous labor } \\
\text { Induced labor } \\
\text { Spontaneous labor } \\
\text { Spontaneous labor }\end{array}$ \\
\hline
\end{tabular}


of pregnanediol during normal pregnancy follows a characteristic course. The daily level of excretion at any stated maturity of pregnancy in a normal patient does not appear to differ markedly from the mean daily norm of that period for a group of patients of comparable body weight. This appears to be true regardless of the size or number of ova in utero, though further data from multiple pregnancies are desirable, since our determinations in this type of gestation are the only ones thus far recorded. It must be noted that a majority of women of the "clinic" type who bear more than one fetus at a time suffer from mild malnutritional anemia and hypoproteinemic edema during the late months of pregnancy. All but one of our cases of multiple gestation exhibited this syndrome. Until the effects of such a complication upon the rate of pregnanediol excretion are investigated, the use for physiologic purposes of the results we have obtained must be tentative. So far as our data suffice, they support the suggestion that the maturity of gestation is a more important factor in determining the levels and rates of pregnanediol excretion than is the mass or number of the fetuses and placentas in utero.

Our data show that the mean levels of excretion at term are no higher than those observed between the 30th and 32nd week. Throughout the last 8 to 10 weeks the minimal values tend to be roughly constant, and are rarely lower than 60 $\mathrm{mgm}$. of pregnanediol per day in normal cases. Continued excretion of less than this amount during the last 10 weeks is therefore definitely abnormal. Diminished excretions of this character have been observed in the "eclampsism" of late pregnancy $(6,8,10)$.

The occurrence of the pre-labor drop in output of pregnanediol in all but one of our patients' individual records suggests that it is a characteristic feature of late pregnancy similar to the pre-labor changes in blood volume, body weight and in the concentration of certain metabolites of the blood stream. A similar prepartal fall has been established for the urinary excretion of estrogens $(17,18)$. In the case of the estrogens Marrian has furthermore noted that the fall is accompanied by a simultaneous drop in the ratio of conjugated estrogen. Although the latter may not be a constant phenomenon, ${ }^{4}$ its finding raises the question whether the pre-labor fall in output of pregnanediol glucuronidate mirrors a true fall in pregnanediol excretion or merely a drop in the proportion of the conjugated steroid. The answer to this must await the further development of methods for the determination of the free steroid in urine.

If it be granted that the output of the glucuronidate of pregnanediol reflects the total excretion of this steroid, comparison of the curve of its excretion with that of the estrogens (18) suggests that the pre-labor peak is reached and passed before the occurrence of the similar peak in the curve of estrogen excretion. The final prepartal fall is therefore probably under way at a time when estrogen clearances are still rising to their maximal gestational levels. In so far as these shifts reflect similar shifts in the internal secretion of progesterone and the estrogens, they afford corroborative evidence of changes which have already been postulated for this period of pregnancy because of the nature of the biologic activity of these hormones, and of the particular rôle which each is believed to play in the initiation of labor (19). In this connection it is of interest that Murphy has regularly obtained among parturient women at this pre-labor period evidence of a gradual increase in uterine irritability and in the rate and strength of spontaneous uterine contractions (20).

Browne, Henry and Venning have noted the transient fluctuations which punctuate the rising gestational curve of pregnanediol excretion (3), but have not ventured to read a definite pattern or physiologic significance into such fluctuations. Our data clearly demonstrate that these fluctuations consist of cyclic monthly remissions, the last of which represents the pre-labor fall previously described. Browne and Venning (21) have reported that a similar cyclic pattern characterizes estrogen excretion in pregnancy. Smith and Smith (11), moreover, have stated that such a pattern may also obtain for the gestational curve of pregnanediol excretion, though no experimental data have so far been submitted.

\footnotetext{
4 Personal communication of Dr. J. S. L. Browne.
} 


\section{SUMMARY AND CONCLUSIONS}

The urinary excretion of sodium pregnanediol glucuronidate was studied by the method of Venning in 6 cases of normal pregnancy at weekly intervals from the 3rd month to full-term, and thereafter at daily intervals for the first 5 days of the puerperium. The results confirm the general findings of Venning, Henry and Browne concerning the normal gestational ranges and levels of the excretion of this compound but show, in addition, that the curve of its excretion is characterized by cyclic monthly fluctuations and by a peak in output during the last month. At the time of labor the rate of excretion is falling.

Additional data from 5 cases of multiple pregnancy indicate that the ranges and levels of excretion in these cases are not markedly different from those of single-fetus gestation, at least during the last half of gestation.

The findings of this study suggest that the rate of excretion of pregnanediol glucuronidate during normal pregnancy is determined by the maturity of gestation rather than by the size or number of fetuses or placentas in utero.

\section{BIBLIOGRAPHY}

1. Venning, E. H., and Browne, J. S. L., Isolation of a water-soluble pregnandiol complex from human pregnancy urine. Proc. Soc. Exper. Biol. and Med., 1936, 34, 792.

2. Venning, E. H., Gravimetric method for the determination of sodium pregnandiol glucuronidate (an excretion product of progesterone). J. Biol. Chem., 1937, 119, 473.

3. Venning, E. H., Further studies on the estimation of small amounts of sodium pregnandiol glucuronidate in urine. J. Biol. Chem., 1938, 126, 595.

4. Venning, E. H., Henry, J. S., and Browne, J. S. L., The measurement of a pregnandiol complex in human urine. Canad. M. A. J., 1937, 36, 83.

5. Browne, J. S. L., Henry, J. S., and Venning, E. H., The corpus luteum hormone in pregnancy. J. Clin. Invest., 1937, 16, 678.

6. Browne, J. S. L., Henry, J. S., and Venning, E. H., The urinary excretion of prolan, estrin, and pregnanediol in normal pregnancy and in early and late pregnancy toxemias. J. Clin. Invest., 1938, 17, 503.
7. Browne, J. S. L., Henry, J. S., and Venning, E. H., The significance of endocrine assays in threatened and habitual abortion. Am. J. Obst. and Gynec., 1939, 38, 927.

8. Weil, P. G., The excretion of pregnandiol in the toxemias of pregnancy. Science, 1938, 87, 72.

9. Jones, H. W., and Weil, P. G., The corpus luteum hormone in early pregnancy; report of case in which there was early removal of corpeus luteum. J. A. M. A., 1938, 111, 519.

10. Smith, G. V., and Smith, O. W., Observations concerning the metabolism of estrogens in women. Am. J. Obst. and Gynec., 1938, 36, 769.

11. Smith, G. V., and Smith, O. W., Estrogen and progestin metabolism in pregnant women. Am. J. Obst. and Gynec., 1940, 39, 405.

12. Wilson, R. B., and Randall, L. M., Studies on pregnandiol. II. The excretion of pregnandiol during normal pregnancy. Proc. Staff Meetings, Mayo Clinic, 1938, 13, 813.

13. Wilson, R. B., Randall, L. M., and Osterberg, A. E., Studies on pregnandiol. Am. J. Obst. and Gynec., 1939, 37, 59.

14. Stover, R. F., and Pratt, J. P., Progestin studies: pregnandiol excretion. Endocrinology, 1939, 24, 29.

15. Taylor, H. C., Jr., and Scadron, E. N., Hormone factors in the toxemias of pregnancy, with special reference to quantitative abnormalities of prolan and estrogens in blood and urine. Am. J. Obst. and Gynec., 1939, 37, 963.

16. Taylor, H. C., Jr., Warner, R. C., and Welsh, C. A., The relationship of the estrogens and other placental hormones to sodium and potassium balance at the end of pregnancy and in the puerperium. Am. J. Obst. and Gynec., 1939, 38, 748.

17. Cohen, S. L., Marrian, G. F., and Watson, M. C., The excretion of oestrin during pregnancy. Lancet, 1935, 1, 674.

18. Smith, G. V., Smith, O. W., and Pincus, G., Total urinary estrogen, estrone and estriol during a menstrual cycle and a pregnancy. Am. J. Physiol., 1938, 121, 98.

19. Reynolds, S. R. M., Physiology of the uterus, with clinical correlations. Hoeber, New York, 1939.

20. Murphy, D. P., Measurements of uterine contractions in late pregnancy; study of 5 patients with the Lorand tocograph. Surg. Gynec. and Obst., 1940, 70, 129.

21. Browne, J. S. L., and Venning, E. M., The assay of urinary estrin and gonadotropic substances during pregnancy. Am. J. Physiol., 1936, 116, 18. 